\title{
The comparison between in-hospital and out-of-hospital death from acute coronary syndrome in the city of Zagreb
}

\author{
Inge Heim* \\ Institute for Cardiovascular Prevention and Rehabilitation, Zagreb, Croatia
}

Background: The Acute Myocardial Infarction Register for the City of Zagreb was established in 1979 in the Institute for Cardiovascular Prevention and Rehabilitation as a population-based register (retrospective study) and in 2003 we established the Acute Coronary Syndrome Register for the City of Zagreb.

Aim: To compare in-hospital and out-of-hospital death from acute coronary syndrome (ACS) by gender and age in the City of Zagreb between 2007 and 2011.

Patients and Methods: Sources of information are: mortality data (Central Bureau of Statistics) and hospital discharge of consecutive patients admitted to all Zagreb hospitals with Acute Cardiology Units. The methodology was previously described-3.

Results: Among 1750 male post-ACS patients, the out-ofhospital death is much higher than in-hospital death $(57 \%$ vs. $43 \%$ ). Men who died outside of hospital are much younger than those who died in hospital (mean age: 66.38 and 72.32, respectively). In-hospital death in 1133 female postACS patients is much higher than out-of-hospital death $(62 \%$ vs. $38 \%)$ and there is no significant difference in age among the women who died in hospital and those who died outside of hospital (mean age: 77.85 and 75.61 , respective- ly). The age distribution among the patients who died in hospital and those who died outside of hospital (Figure 1) shows differences especially in out-of-hospital death from ACS in men reaching peak between 55 and 74 years of age and both in- and out-of-hospital death between 65 and 74 years of age. In women in-hospital death reaches a peak between 75-84 years of age (Figure 2).

Conclusion: The comparison between in-hospital and outof-hospital death from ACS by gender and age shows great differences. In-hospital death in women is significantly higher than out-of-hospital death. Men who died outside of hospital are 10 years younger than women and younger than men who died in hospital. Obviously, the outcome of the acute coronary syndrome depends on gender, age and clinical presentation. From the epidemiological point of view, the emphasis should be placed on cardiovascular prevention, population education which would enable a quick transport to hospital with a a catheterization laboratory. The AMI/ACS population-based register gives the information on the characteristics, burden and consequences of ACS in the City of Zagreb and is intended for health professionals and policymakers.

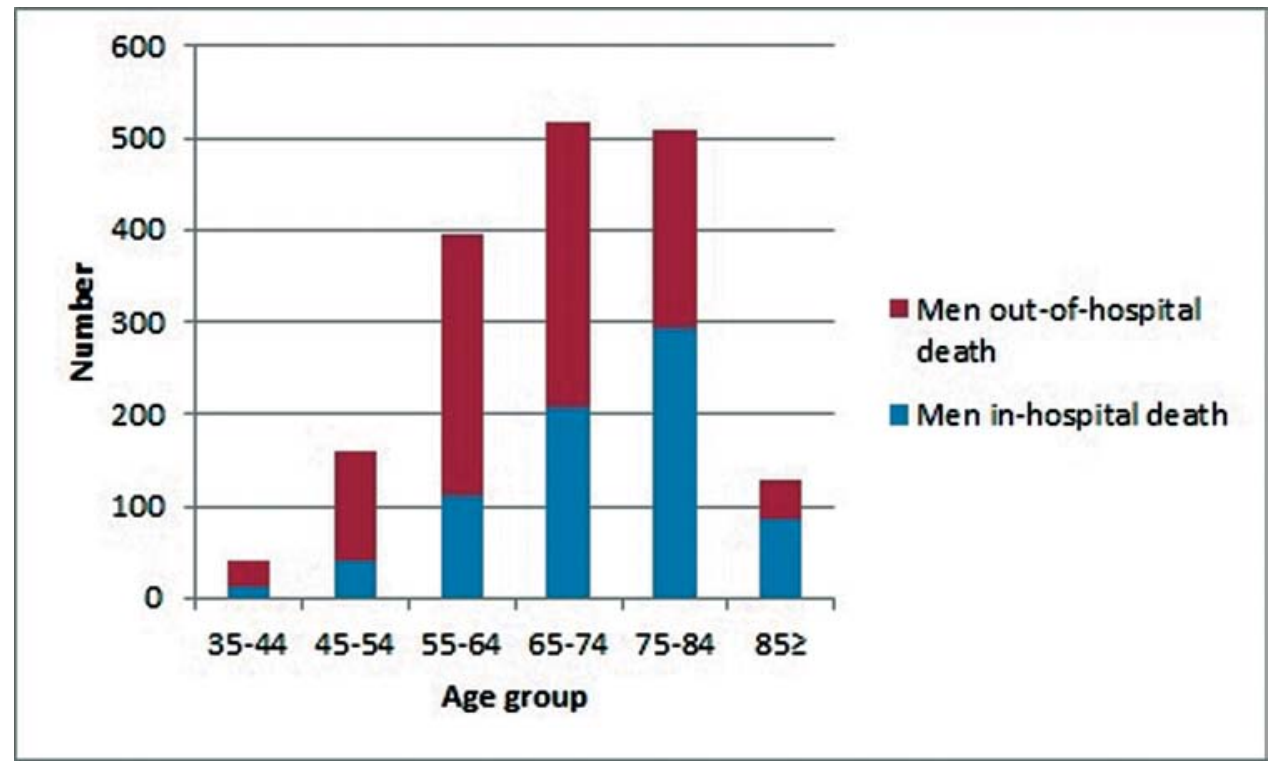

Source: Croatian Bureau of Statistics

Figure 1. Comparison of in- and out-of-hospital death from ACS among men by age - Zagreb residents (2007 - 2011). 


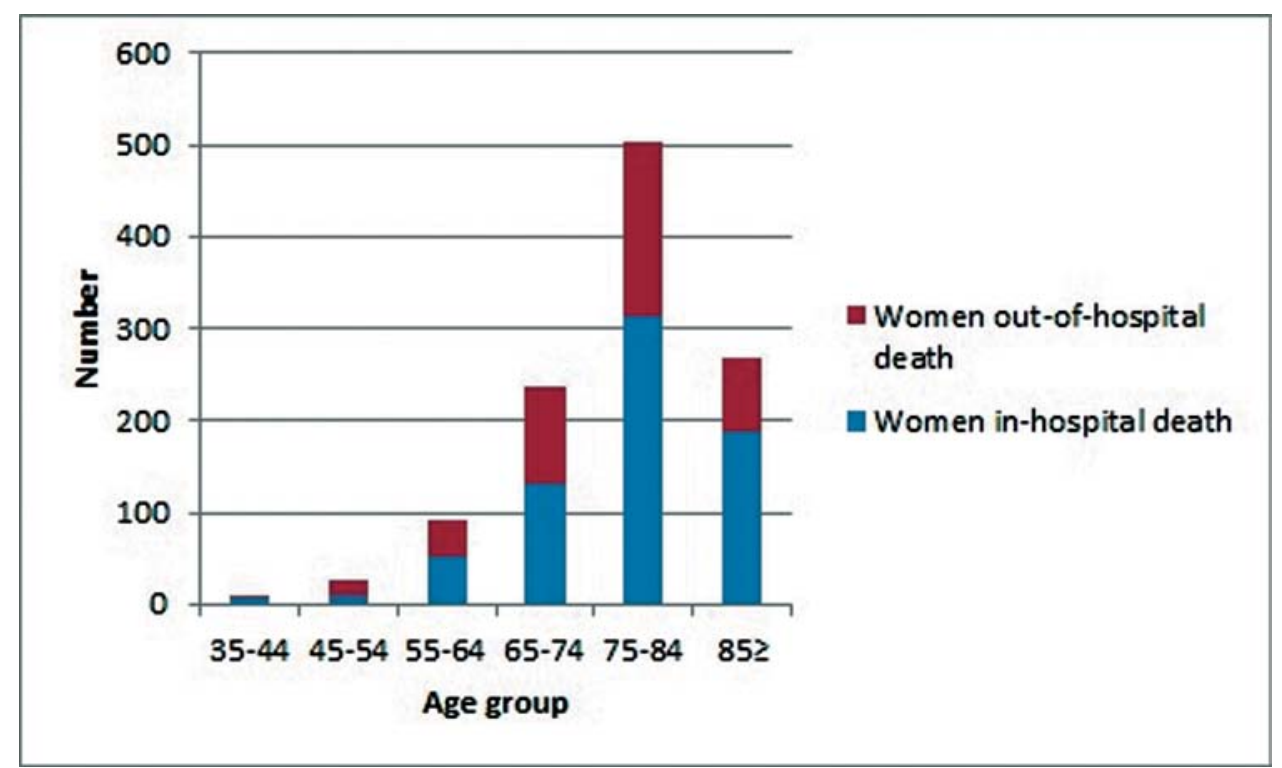

Source: Croatian Bureau of Statistics.

Figure 2. Comparison of in- and out-of-hospital death from ACS among women by age - Zagreb residents (2007 - 2011).

\section{Received: $1^{\text {st }}$ May 2014}

*Address for correspondence: Poliklinika za prevenciju kardiovaskularnih bolesti I rehabilitaciju, Draškovićeva 13, HR-10000 Zagreb, Croatia.

Phone: $+385-1-4612-308$

Fax: +385-1-4612-343

E-mail: inge.heim@srcana.hr
KEYWORDS: acute coronary syndrome, epidemiology, population-based register, mortality, in-hospital death, out-ofhospital death.

CITATION: Cardiol Croat. 2014;9(5-6):162-163.

\section{Literature}

1..Heim I. The process of collecting data for the Acute Myocardial Infarction / Acute Coronary Syndrome Register for the City of Zagreb. Cardiol Croat. 2014;9(3-4):100-1.

2. Heim I. Jonke V, Gostović M, Jembrek-Gostović M. [Epidemiology of acute coronary syndrome in the City of Zagreb]. Acta Med Croatica. 2009;63:105-9.

3. Peršić V, Miletić B, Boban M, et al. Cardiovascular prevention and rehabilitation: where are we and where are we heading to? Cardiol Croat. 2012;7(5-6):158-169. 